\title{
Caracterização ecotoxicológica de um novo fenilbenzotriazol sintetizado a partir do corante C.I. Disperse Violet 93
}

\author{
Natália G. Camparotto*, Josiane A. S. Vendemiatti , Patrícia Prediger
}

\section{Resumo}

Este projeto refere-se a avaliação da toxicidade crônica de um novo fenilbenzotriazol, além do desenvolvimento de metodologias para a extração e quantificação do composto em água.

\section{Palavras-chave:}

Ecotoxicidade, corantes dinitrofenilazos, método analítico

\section{Introdução}

Fenilbenzotriazóis (PBTA) podem ser formados a partir de reações de redução de corantes da classe dinitrofenilazo durante os processos de tingimento em indústrias têxteis ${ }^{1}$. A ocorrência desses compostos no ambiente já foi relatada devido à ineficiência dos processos convencionais de tratamento de efluentes contendo estas substâncias. Os métodos mais utilizados para a extração de PBTA de amostras ambientais foram blue rayon e extração em fase sólida (SPE). Entretanto, o método de extração líquido-líquido por salting-out (do inglês SALLE) tem demonstrado ser simples e eficiente para corantes e compostos de polaridade média ${ }^{2}$. Recentemente um novo 2-fenilbenzotriazol foi sintetizado em nosso laboratório a partir da redução do corante C.I. Disperse Violet 93. Os objetivos deste trabalho foram realizar testes de toxicidade crônica com a alga Pseudokirchneriella subcapitata e o microcrustáceo Daphnia similis para o cálculo do PNEC (Predicted Non Effect Concentration) e desenvolver um novo método de extração viável para a determinação do 2-fenilbenzotriazol em amostras ambientais de água superficial.

\section{Resultados e Discussão}

A toxicidade crônica do composto foi determinada para $D$. similis e $P$. subcapitata e o composto se mostrou mais tóxico para o microcrustáceo (Tabela 1). O PNEC calculado foi $2 \mathrm{ng} \mathrm{L}^{-1}$.

Tabela 1. Toxicidade crônica do 2-fenilbenzotriazol

\begin{tabular}{cccc} 
Organismo & Exposição & \multicolumn{2}{c}{ Valor observado } \\
\hline D. similis & 14 dias $^{\mathrm{a}}$ & $\mathrm{CENO}^{3}$ & $0,1 \mu \mathrm{g} \mathrm{L}^{-1}$ \\
\hline P. subcapitata & 72 horas $^{\mathrm{b}}$ & $\mathrm{CENO}^{4}$ & $100 \mu \mathrm{g} \mathrm{L}^{-1}$ \\
\hline End point: $\mathrm{a}=$ inibição da reprodução; $\mathrm{b}=$ inibição do crescimento.
\end{tabular}

Com relação aos métodos cromatográficos, a curva analítica do 2-fenilbenzotriazol apresentou uma boa linearidade nas concentrações de 0,1 a $300 \mu \mathrm{g} \mathrm{L}^{-1}$ $\left(R^{2}=0,9918\right)$, limite de quantificação de $26 \mu \mathrm{g} \mathrm{L}^{-1}$ e limite de detecção de $8 \mu \mathrm{g} \mathrm{L}^{-1}$ (Figura 1). A eficiência da recuperação do SALLE foi testada usando-se água de rio como matriz em três diferentes $\mathrm{pH}(7,4$ e 8$)$. No $\mathrm{pH}$ natural da amostra $(\sim \mathrm{pH} 7)$ e no pH 8 a eficiência no processo de extração do 2-fenilbenzotriazol foi melhor (Tabela 2). Esse fato pode ser explicado pelo fato da molécula ser protonada e ficar mais solúvel em água, diminuindo a eficiência de transferência para o solvente orgânico em pH ácido. Apesar de apresentar menor porcentagem de recuperação, o coeficiente de variação das médias (CV) foi melhor para o $\mathrm{pH} 8$, abaixo de $20 \%$.

Figura 1. Curva analítica do 2-fenilbenzotriazol

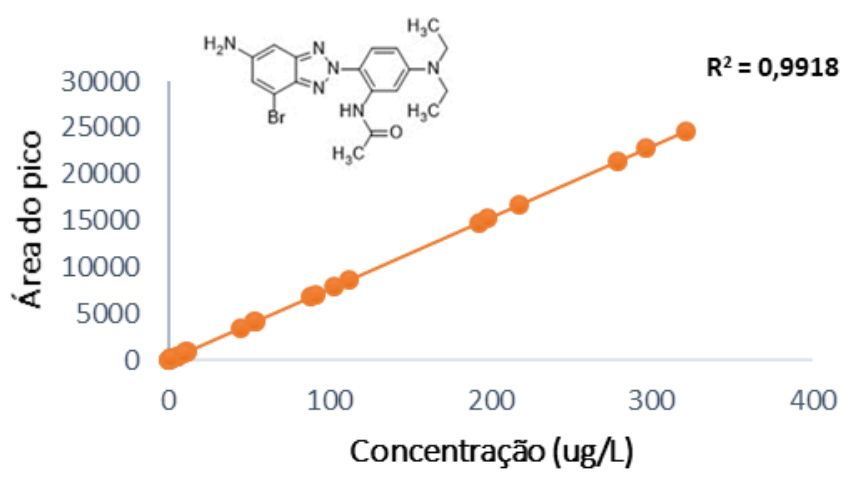

Condições da separação cromatográfica: coluna Zorbax SB-C18 (2,1×30 $\mathrm{mm})$, fase móvel $70 \%$ metanol/água $(0,1 \%$ ácido fórmico). Taxa de fluxo= $0,3 \mathrm{ml} \mathrm{min}^{-1}$, metanol de $65 \%$ a $80 \%$.

Tabela 2. Eficiência na extração do 2-fenilbenzotriazol

\begin{tabular}{cccc} 
& \multicolumn{3}{c}{ \% Recuperação do 2-fenilbenzotriazol } \\
\cline { 2 - 4 } & $\mathbf{p H 7}$ & $\mathbf{p H 4}$ & $\mathbf{p H 8}$ \\
\hline Réplica 1 & 43 & 8 & 25 \\
Réplica 2 & 26 & 12 & 33 \\
Réplica 3 & 31 & 7 & 26 \\
\hline Média & 33 & 9 & 28 \\
DP & 9 & 3 & 4 \\
CV (\%) & 26 & 32 & 15 \\
\hline
\end{tabular}

Método: $25 \mathrm{~mL}$ de amostra (spike $100 \mu \mathrm{g} \mathrm{L}-1$ ); $2,5 \mathrm{~g} \mathrm{NaCl}+0,5 \mathrm{~g} \mathrm{MgSO}_{4}$; solvente de extração: $10 \mathrm{~mL}$ acetonitrila; 1 min vórtex; $10 \mathrm{~min}(10000 \mathrm{~g}$ ); ressuspensão do extrato seco: $1000 \mathrm{~mL}$ de $70 \% \mathrm{MeOH} / \mathrm{H}_{2} \mathrm{O}$; concentração: 25 vezes.

\section{Conclusões}

A derivação do PNEC de $2 \mathrm{ng} \mathrm{L}^{-1}$ demonstrou que 0 2fenilbenzotriazol é muito tóxico para a biota aquática. $\mathrm{O}$ método de extração demonstrou um DP e CV adequados para $\circ \mathrm{pH} 8$, porém com uma baixa recuperação o que prejudicaria a determinação do 2-fenilbenzotriazol em amostras de rio em níveis mais baixos. Para a avaliação de risco do composto serão necessárias novas otimizações do método.

\section{Agradecimentos}

Processo FAPESP 2015/07033-7; CAPES; CNPq; FAEPEX.

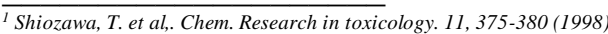

${ }_{2}^{2}$ Reza S. Razmara, Ali Daneshfar *, Reza Sahrai Department, Journal of Industrial and Engineering Chemistry 17, 533-536 (2011).

${ }^{3}$ Hamilton, M. A., Russo, R. C. \& Thurston, R. V. Environ. Sci. Technol. 11, 714-719 (1977).

${ }^{4}$ Norberg-King, T. J. A linear interpolation method for sublethal toxicity: the inhibition concentration (ICp) approach. (1993) 